\title{
Impact of acute diabetes decompensation on outcomes of diabetic patients admitted with ST-elevation myocardial infarction
}

\author{
Mayada Issa ${ }^{1 \dagger}$, Fahad Alqahtani ${ }^{2 \dagger}$, Chalak Berzingi ${ }^{2}$, Mohammad Al-Hajji ${ }^{2}$, Tatiana Busu ${ }^{2}$ \\ and Mohamad Alkhouli2, $3^{*}$ (1)
}

\begin{abstract}
Background: Acute hyperglycemia is associated with worse outcomes in diabetic patients admitted with ST-elevation myocardial infarction (STEMI). However, the impact of full-scale decompensated diabetes on STEMI outcomes has not been investigated.

Methods: We utilized the national inpatient sample (2003-2014) to identify adult diabetic patients admitted with STEMI. We defined decompensated diabetes as the presence of diabetic ketoacidosis (DKA) or hyperglycemic hyperosmolar state (HHS). We compared in-hospital morbidity and mortality and cost between patients with and without diabetes decompensation before and after propensity-score matching.
\end{abstract}

Results: A total of 73,722 diabetic patients admitted with STEMI were included in the study. Of those, 1131 (1.5\%) suffered DKA or HSS during the hospitalization. After propensity-score matching, DKA/HHS remained associated with a significant 32\% increase in in-hospital mortality (25.6\% vs. 19.4\%, $p=0.001)$. The DKA/HHS group also had higher incidences of acute kidney injury (39.4\% vs. 18.9\%, $\mathrm{p}<0.001)$, sepsis (7.3\% vs. 4.9\%, $\mathrm{p}=0.022$ ), blood transfusion ( $11.3 \%$ vs. 8.2\%) and a non-significant trend towards higher incidence of stroke (3.8\% vs. 2.4\%, $\mathrm{p}=0.087)$. Also, DKA/HHS diagnosis was associated with lower rates of referral to coronary angiography $(51.5 \%$ vs. $55.5 \%, p=0.023)$, coronary stenting (26.1\% vs. 34.8\%, p<0.001), or bypass grafting (6.2\% vs. 8.7\%, $p=0.033)$. Referral for invasive angiography was associated with lower odds of death during the hospitalization (adjusted OR 0.66, 95\% Cl 0.44-0.98, p=0.039).

Conclusions: Decompensated diabetes complicates $1.5 \%$ of STEMI admissions in diabetic patients. It is associated with lower rates of referral for angiography and revascularization, and a negative differential impact on in-hospital morbidity and mortality and cost.

Keywords: Myocardial infarction, Diabetic ketoacidosis, Hyperosmolar hyperglycemic state, Coronary angiography, Coronary stenting

\footnotetext{
*Correspondence: Mohamad.Alkhouli@wvumedicine.org

${ }^{\dagger}$ Mayada Issa and Fahad Alqahtani contributed equally to this manuscript

${ }^{3}$ West Virginia University Heart \& Vascular Institute, 1 Medical Drive,

Morgantown, WV 26505, USA

Full list of author information is available at the end of the article
}

(c) The Author(s) 2018. This article is distributed under the terms of the Creative Commons Attribution 4.0 International License (http://creativecommons.org/licenses/by/4.0/) which permits unrestricted use, distribution, and reproduction in any medium, provided you give appropriate credit to the original author(s) and the source, provide a link to the Creative Commons license, and indicate if changes were made. The Creative Commons Public Domain Dedication waiver (http://creativecommons.org/ publicdomain/zero/1.0/) applies to the data made available in this article, unless otherwise stated. 


\section{Background}

The impact of acute hyperglycemia on clinical outcomes of diabetic and non-diabetic patients admitted with ST-elevation myocardial infarction (STEMI) has been extensively studied. High admission blood glucose among STEMI patients is associated with higher shortterm incidences of failed reperfusion, acute kidney injury, stent thrombosis, myocardial damage and death among [1-12]. In addition, hyperglycemia during STEMI hospitalizations in diabetics predicted left ventricular remodeling and survival during long-term follow-up [13-18]. However, large-scale outcomes data of STEMI patients with acutely decompensated diabetes manifesting as diabetic ketoacidosis (DKA) or hyperglycemic hyperosmolar state (HHS) are scarce [11]. We utilized a nationwide representative sample to assess the contemporary trends in the incidence and in-hospital morbidity and mortality and cost of decompensated diabetes (defined as DKA or HSS) among diabetic patients admitted with STEMI.

\section{Methods}

\section{Study data}

The National Inpatient Sample (NIS) was used to derive patient relevant information between January, 1st 2003 and December, 31st 2014. The NIS is the largest publicly available all-payer administrative claims-based database and contains information about patient discharges from approximately 1000 non-federal hospitals in 45 states. It contains clinical and resource utilization information on 5-8 million discharges annually, with safeguards to protect the privacy of individual patients, physicians, and hospitals. These data are stratified to represent approximately $20 \%$ of US inpatient hospitalizations across different hospital and geographic regions (random sample). National estimates of the entire US hospitalized population were calculated using the Agency for Healthcare Research and Quality sampling and weighting method.

\section{Study population}

Patients $>18$-year-old with a principle discharge diagnosis of ST-elevation myocardial infarction (International Classification of Diseases-Ninth Revision-Clinical Modification [ICD-9-CM] codes 410.×1 except 410.71) between 2003 and 2014 were identified in the NIS. Nondiabetic patients were then excluded yielding a cohort of diabetic patients admitted with STEMI. Those were then stratified into patients with or without decompensated diabetes. Similar to prior studies, we defined decompensated diabetes was defined as: diabetes with ketoacidosis (ICD-9-CM codes 250.10-250.13) or diabetes with hyperosmolaity (ICD-9-CM codes 250.20-250.23) $[19,20]$. Myocardial infarction codes used in this study have a negative predictive value of $96.1 \%$, and a positive predictive value of $95.9 \%$ and are similar to what has been reported in other studies [21, 22].

\section{Outcomes analysis and study endpoints}

A comparative analysis was performed between diabetic patients admitted with STEMI with and without DKA/ HSS before and after propensity score matching for the primary end point of in-hospital mortality, and for the secondary end points of in-hospital complications, length of stay, post-discharge intermediate care utilization and cost.

To account for potential confounding factors and reduce the effect of selection bias, a propensity scorematching model was developed using logistic regression to derive two matched groups for the comparative outcomes analysis. Patients admitted with STEMI with or without DKA/HHS were entered into a nearest neighbor 1:1 variable ratio, parallel, balanced propensity-matching model using a caliper of 0.01 without replacement to ensure perfect matching. Variables included in the propensity match model are listed in Additional file 1: Table S1.

We anticipated that decompensated diabetes will have a differential impact on referral patterns for invasive angiography. We hence examined the impact of invasive angiography referral on in-hospital mortality among patients with decompensated diabetes using a multivariable logistical regression analysis model.

\section{Statistical analysis}

Descriptive statistics presented as frequencies with percentages for categorical variables and as means with standard deviations for continuous variables. Baseline characteristics were compared using a Pearson Chi squared test and Fisher's exact test for categorical variables and an independent-samples $t$ test for continuous variables. Matched categorical variables were presented as frequencies with percentages and compared using McNamar's test. Matched continuous variables were presented as means with standard deviations and compared using a paired-samples t-test. A type I error rate of $<0.05$ was considered statistically significant. To assess monotonic trends of utilization and outcomes we employed the non-parametric Mann-Kendal trend method. All statistical analyses were performed using SPSS version 24 (IBM Corporation, Armonk, NY) and R, version 3.3.1.

\section{Results}

A total of 73,722 diabetic patients (weighted national estimate $=362,362$ ) admitted with STEMI between January 1st, 2003 and December 31st, 2014 were included in the study. Of those, 72,591 patients (98.5\%) had compensated diabetes and 1131 (1.5\%) suffered DKA or HSS 
during the hospitalization with modest temporal increase in this incidence during the study period (Fig. 1). Patients with DKA/HHS were younger ( $63 \pm 15$ vs. $67 \pm 15$ years, $\mathrm{p}<0.001)$ and a distinctive risk profile compared with diabetic patients without DKA/HHS, characterized with lower incidences of hypertension, hyperlipidemia, smoking, chronic obstructive lung disease, known coronary artery disease, and prior atrial fibrillation (Table 1).

Patients with decompensated diabetes had higher incidences of cardiogenic shock (23.9\% vs. $9.3 \%$ ), and cardiac arrest $(11.8 \%$ vs. $5.6 \%)$, and were less likely to undergo coronary angiography (51.4\% vs. $61.1 \%)$, percutaneous coronary intervention (PCI) $(25.8 \%$ vs. $40 \%)$, or coronary bypass grafting $(6.2 \%$ vs. $9.2 \%)(\mathrm{P}<0.001$ for all) (Tables 1 , $2)$. However, referral to coronary angiography and PCI increased overtime (Fig. 2).

\section{Outcomes of the unmatched cohorts}

Compared with patients with decompensated diabetes, those with DKA/HHS had over twofold higher in-hospital mortality $(26.4 \%$ vs. $11.9 \%, \mathrm{p}<0.001)$ and higher incidences of acute kidney injury (40\% vs. 13.3\%), stroke (3.7\% vs. $1.6 \%)$, sepsis $(7.5 \%$ vs. $1.9 \%)$, blood transfusion $(11.3 \%$ vs. $8.2 \%)$ and mechanical ventilation $(8.6 \%$ vs. $2.9 \%),(\mathrm{p}<0.001$ for all). They also had longer hospitalizations $(7 \pm 8$ vs. $5 \pm 6$ days, $\mathrm{p}<0.001)$, higher hospital charges $(87,382 \pm 132,119 \$$ vs. $64,396 \pm 81,185 \$$, $\mathrm{p}<0.001$ ), and were less likely to be discharged directly to home $(58.7 \%$ vs. $68.4 \%, \mathrm{p}<0.001)$ (Table 3$)$.

\section{Outcomes of the matched cohorts}

Following propensity-score matching, baseline characteristics between the two sets of STEMI patients with and without DKA/HHS became well matched (Additional file 1: Table 2 and Figure S1). The presence of DKA/ HHS remained associated with significantly lower rates of referral to coronary angiography $(52.2 \%$ vs. $57.1 \%$, $\mathrm{p}=0.023)$, and PCI $(29.5 \%$ vs. $38.4 \%, \mathrm{p}<0.001)$ (Additional file 1: Table S3). In these propensity-matched cohorts, DKA/HHS remained associated with a significant $32 \%$ increase in in-hospital mortality $(25.6 \%$ vs. $19.4 \%, p=0.001)$. The DKA/HHS group also had significantly higher incidences of acute kidney injury $(39.4 \%$ vs. $18.9 \%, \mathrm{p}<0.001)$, sepsis $(7.3 \%$ vs. $4.9 \%, \mathrm{p}=0.022)$, and a non-significant trend towards higher stroke $(3.8 \%$ vs. $2.4 \%, \mathrm{p}=0.087)$. Similar to the unmatched cohorts, they also had longer hospitalizations, higher hospital charges and were less likely to be discharged directly to home (Table 3).

Given that patients in the decompensated diabetes group were less likely to be referred for invasive angiography and they also had higher in-hospital mortality, the impact of invasive angiography referral on in-hospital mortality among these patients was examined using a multivariable logistical regression analysis model. This model adjusted for demographics, baseline clinical risk factors, insurance status and hospital characteristic, and showed that referral for invasive angiography was associated with lower odds of death during the hospitalization

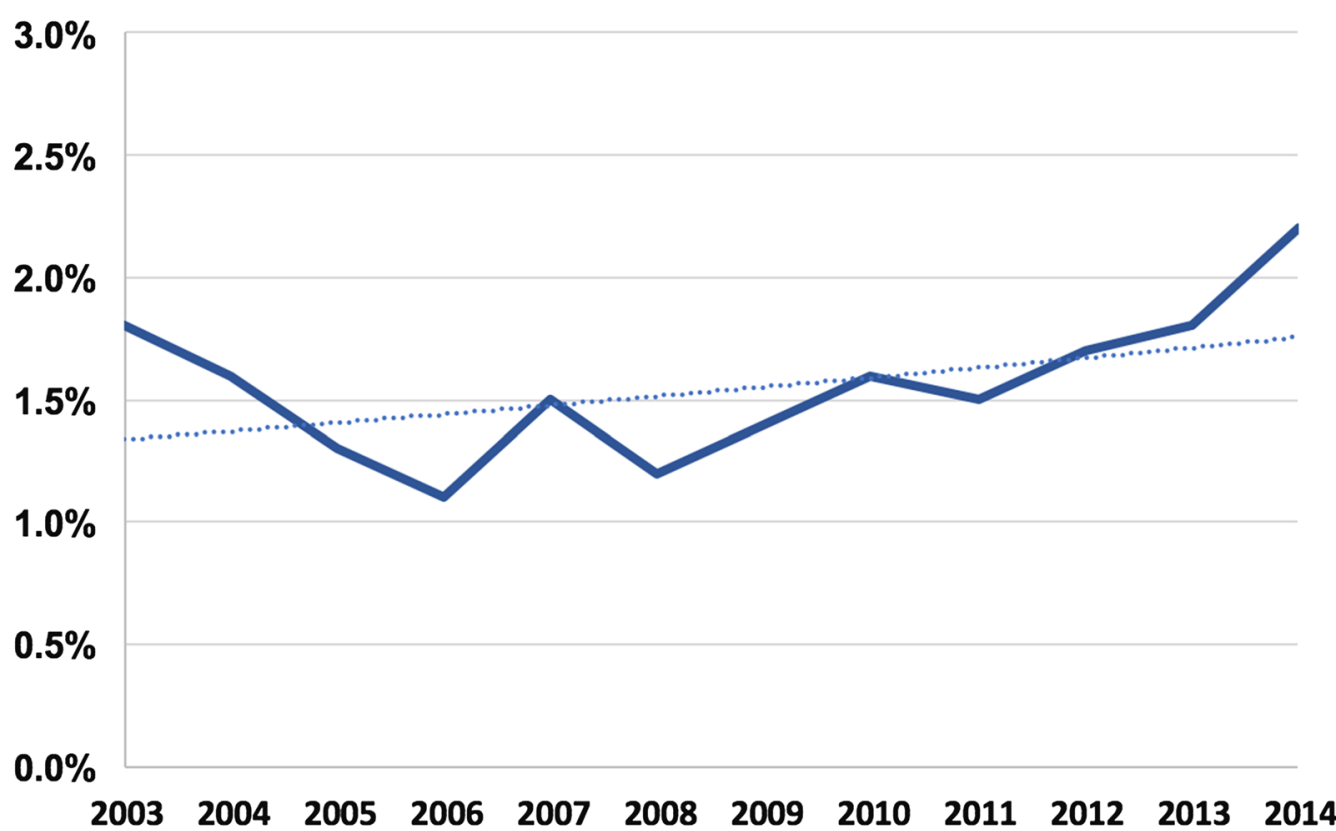

Fig. 1 Trends in the incidence of decompensated diabetes among diabetic patients admitted with STEMI 
Table 1 Baseline characteristics of the study's population

\begin{tabular}{|c|c|c|c|}
\hline Baseline characteristics & $\begin{array}{l}\text { Compensated diabetes } \mathrm{N}=72,591 \\
\mathrm{NE}=356,810\end{array}$ & $\begin{array}{l}\text { Decompensated diabetes } \mathrm{N}=1113 \\
\mathrm{NE}=5553\end{array}$ & $P$ value \\
\hline Age-mean (SD), years & $64 \pm 14$ & $63 \pm 15$ & $<0.001$ \\
\hline Female & $41.0 \%$ & $47.3 \%$ & $<0.001$ \\
\hline Race & & & 0.752 \\
\hline Caucasian & $70.5 \%$ & $70.1 \%$ & \\
\hline African American & $10.5 \%$ & $11.5 \%$ & \\
\hline Hispanic & $11.1 \%$ & $11.2 \%$ & \\
\hline Dyslipidemia & $52.3 \%$ & $32.4 \%$ & $<0.001$ \\
\hline Hypertension & $70.8 \%$ & $51.7 \%$ & $<0.001$ \\
\hline Prior sternotomy & $7.3 \%$ & $6.5 \%$ & 0.361 \\
\hline Chronic lung disease & $18.2 \%$ & $13.7 \%$ & $<0.001$ \\
\hline Atrial fibrillation/flutter & $15.5 \%$ & $12.0 \%$ & 0.001 \\
\hline Anemia & $16.1 \%$ & $19.4 \%$ & 0.003 \\
\hline Coagulopathy & $4.0 \%$ & $7.5 \%$ & $<0.001$ \\
\hline Conduction abnormality & $5.8 \%$ & $7.2 \%$ & 0.05 \\
\hline Congestive heart failure & $0.7 \%$ & $4.7 \%$ & $<0.001$ \\
\hline Cardiogenic shock & $9.3 \%$ & $23.9 \%$ & $<0.001$ \\
\hline Drug abuse & $1.4 \%$ & $3.3 \%$ & $<0.001$ \\
\hline Smoking & $26.6 \%$ & $20.6 \%$ & $<0.001$ \\
\hline Vascular disease & $10.4 \%$ & $8.8 \%$ & 0.077 \\
\hline Coronary artery disease & $64.6 \%$ & $48.4 \%$ & $<0.001$ \\
\hline Prior stroke & $3.3 \%$ & $2.6 \%$ & 0.182 \\
\hline Chronic renal failure & $17.4 \%$ & $21.2 \%$ & 0.001 \\
\hline Liver disease & $1.1 \%$ & $2.0 \%$ & 0.005 \\
\hline Teaching hospital & $43.2 \%$ & $44.8 \%$ & 0.285 \\
\hline Rural hospital location & $15.1 \%$ & $12.5 \%$ & 0.016 \\
\hline Primary payer-no (\%) & & & $<0.001$ \\
\hline Medicare/medicaid & $65.1 \%$ & $62.0 \%$ & \\
\hline Private insurance & $25.3 \%$ & $24.8 \%$ & \\
\hline Self-pay & $6.0 \%$ & $9.8 \%$ & \\
\hline No charge/other & $3.7 \%$ & $3.4 \%$ & \\
\hline
\end{tabular}

$S D$ standard deviation

Table 2 Management patterns in the unmatched cohorts

\begin{tabular}{lllr}
\hline Management & $\begin{array}{l}\text { Compensated } \\
\text { diabetes } \\
\mathbf{N = 7 2 , 5 9 1} \\
\mathbf{N E = 3 5 6 , 8 1 0} \\
(\%)\end{array}$ & $\begin{array}{l}\text { Decompensated } \\
\text { diabetes } \\
\mathbf{N}=\mathbf{1 1 1 3}\end{array}$ & $\begin{array}{c}\boldsymbol{P} \text { value } \\
\mathbf{N E}=\mathbf{5 5 5 3}(\%)\end{array}$ \\
& & & \\
\hline Coronary angiography & 62.9 & 52.3 & $<0.001$ \\
Coronary intervention & 43.2 & 29.6 & $<0.001$ \\
IV thrombolysis & 1.8 & 1.3 & 0.218 \\
Underwent PTCA & 3.2 & 3.7 & 0.308 \\
Underwent PCI & 40.0 & 25.8 & $<0.001$ \\
BMS & 27.4 & 15.4 & $<0.001$ \\
DES & 13.4 & 10.8 & $<0.001$ \\
\hline
\end{tabular}

PTCA percutaneous transluminal coronary angiography, $I V$ intravenous, $P C I$ percutaneous coronary intervention, $B M S$ bare metal stent, $D E S$ drug eluting stent (adjusted OR 0.66, 95\%CI 0.44-0.98, $\mathrm{p}=0.039$ ). Variables included in this regression models are the same variables used for propensity score matching outlined in Additional file 1: Table S1.

\section{Discussion}

The main findings of the present investigation are: (1) acute diabetes decompensation occur in $1.5 \%$ of diabetics admitted with STEMI, (2) those patients have less prevalence of previously diagnosed coronary artery disease, but higher incidences of cardiogenic shock and cardiac arrest, (3) patients with decompensated diabetes were less likely to undergo coronary angiography and revascularization compared with patients with compensated diabetes, (4) referral to angiography was independently associated with lower risk-adjusted odds of in-hospital 


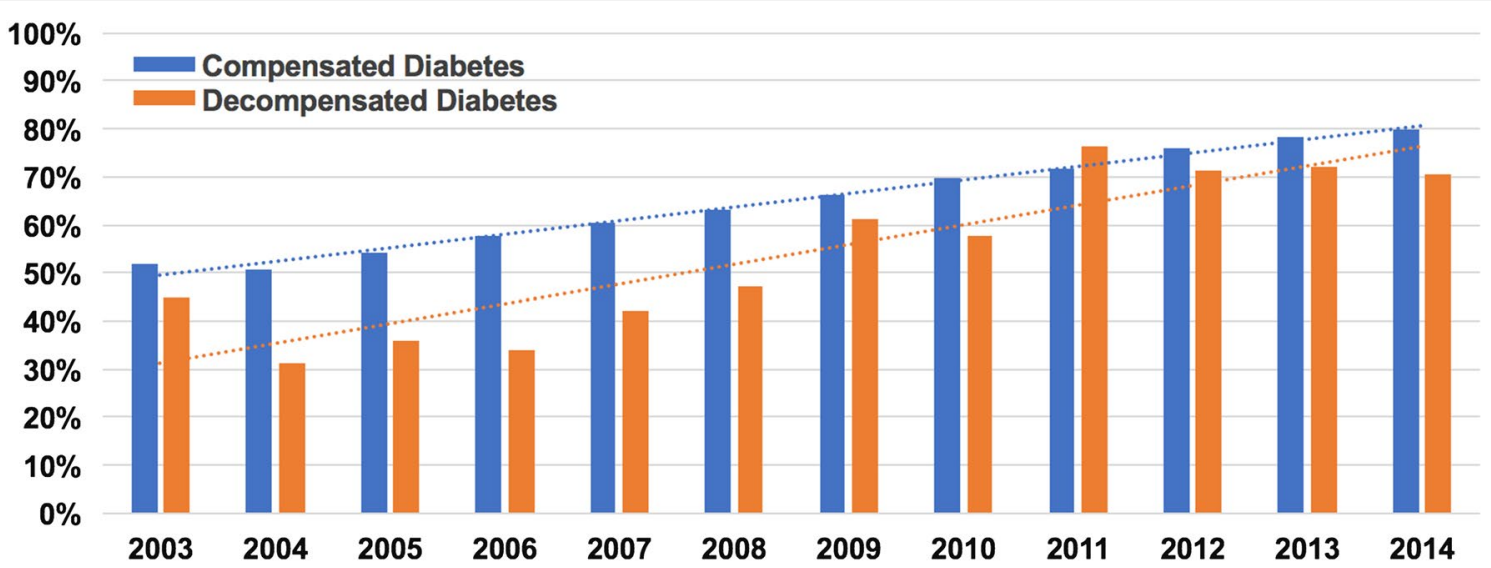

Fig. 2 Trends in percutaneous coronary revascularization among diabetic patients admitted with STEMI

Table 3 In-hospital outcomes of STEMI patients with and without DKA/HHS

\begin{tabular}{|c|c|c|c|c|c|c|}
\hline \multirow[t]{2}{*}{ Clinical outcome } & \multicolumn{3}{|c|}{ Unmatched cohorts } & \multicolumn{3}{|l|}{ Matched cohorts } \\
\hline & $\begin{array}{l}\text { Compensated } \\
\text { diabetes } \\
N=72,591 \\
N E=356,810 \\
(\%)\end{array}$ & $\begin{array}{l}\text { Decompensated diabetes } \\
\mathrm{N}=1113 \mathrm{NE}=5553(\%)\end{array}$ & $\begin{array}{l}P \\
\text { value }\end{array}$ & $\begin{array}{l}\text { Compensated diabetes } \\
\mathrm{N}=1103 \mathrm{NE}=5410(\%)\end{array}$ & $\begin{array}{l}\text { Decompensated diabetes } \\
\mathrm{N}=1103 \mathrm{NE}=5410(\%)\end{array}$ & $P$ value \\
\hline Death & 11.9 & 26.4 & $<0.001$ & 19.4 & 25.6 & 0.001 \\
\hline Blood transfusion & 8.2 & 11.3 & $<0.001$ & 11.7 & 11.1 & 0.689 \\
\hline Acute kidney injury & 13.3 & 40.0 & $<0.001$ & 18.9 & 39.4 & $<0.001$ \\
\hline New dialysis & 0.4 & 0.5 & 0.521 & 0.5 & 0.5 & 0.99 \\
\hline Stroke & 1.6 & 3.7 & $<0.001$ & 2.4 & 3.8 & 0.087 \\
\hline UTI & 7.4 & 13.1 & $<0.001$ & 8.3 & 13.1 & 0.001 \\
\hline Sepsis & 1.9 & 7.5 & $<0.001$ & 4.9 & 7.3 & 0.022 \\
\hline Acquired pneumonia & 6.6 & 12.0 & $<0.001$ & 7.5 & 12.1 & $<0.001$ \\
\hline Mechanical ventilation & 2.9 & 8.6 & $<0.001$ & 7.1 & 8.0 & 0.456 \\
\hline Tracheostomy & 0.6 & 1.5 & $<0.001$ & 2.6 & 1.0 & 0.006 \\
\hline Discharged home & 60.3 & 43.3 & $<0.001$ & 51.0 & 44.1 & 0.01 \\
\hline Discharged to IC & 26.9 & 29.1 & & 28.3 & 29.2 & \\
\hline LOS (mean \pm SD) & $5 \pm 6$ & $7 \pm 8$ & $<0.001$ & $6 \pm 7$ & $7 \pm 7$ & 0.02 \\
\hline Total charges (\$) & $64,396 \pm 81,185$ & $87,382 \pm 132,119$ & $<0.001$ & $76,983 \pm 109,872$ & $84,527 \pm 125,828$ & 0.133 \\
\hline
\end{tabular}

UTI urinary tract infection, IC intermediate care facility, SD standard deviation, LOS length of stay

death in patients with decompensated diabetes, and (5) acute diabetes decompensation was associated with $32 \%$ higher in-hospital mortality, higher incidences of certain key morbidities, more resource utilization, and higher cost.

Prior studies have shown that the hyperglycemia during STEMI admissions is not uncommon in both diabetics and non-diabetics, and hyperglycemia in this setting is associated with worse short and long-term outcomes [1-18]. Nonetheless, to our knowledge, the incidence of full-scale uncontrolled hyperglycemia (decompensated diabetes) manifesting as DKA or HHS and its impact on clinical outcomes among STEMI patients have not been previously investigated.

Our analysis reveals that the incidence of DKA or HHS among diabetic patients admitted with STEMI is low $(1.5 \%)$ but is associated with lower odds of undergoing revascularization, and higher morbidity and mortality and cost. Albeit intuitive, the findings of our study deserve more scrutiny:

1. The lower prevalence of known coronary artery disease and the worse initial presentation (evident by 
the higher incidence of cardiogenic shock and cardiac arrest) in the DKA/HHS population are absorbing. Although speculative, these patients may have constituted a different cohort of patients at baseline that is characterized with worse chronic glycemic control, attenuated symptoms due to diabetic neuropathy, delayed presentations, and possibly larger infarcts $[23,24]$.

2. The interrelation between DKA/HHS and worse outcomes in STEMI patients is rather complex and may be difficult to unravel from cohort analyses like the present one. Several studies have shown than uncontrolled hyperglycemia is associated with high plasma catecholamine levels, oxidative stress, and endothelial and microvascular dysfunction possibly leading to higher incidence of no reflow, larger infarcts and hence worse STEMI outcomes [1, 25, 26]. Vice versa, the occurrence of DKA/HHS during a STEMI admission may be related to worse STEMI profile in these patients (cardiogenic shock or cardiac arrest). These patients may experience more intense hemodynamic and hormonal derangements and hence may develop DKA or HHS as a result for their "higherrisk' STEMI. Further studies are needed to delineate the impact of variable degrees of hyperglycemia on STEMI outcomes and to identify the associated underlying mechanisms.

3. Patients with DKA/HHS were less likely to be referred to angiography, although this has improved with time. Reasons for this 'less invasive' practice are not known and can not be ascertained in our study. Nonetheless, referral for angiography was independently associated with improved in hospital survival suggesting a potential opportunity for improvement in this cohort.

4. The excess associated mortality of DKA/HHS was significantly attenuated after rigorous propensity score matching: $26.4 \%$ vs. $11.9 \%, \mathrm{p}<0.001$ before matching, and $25.6 \%$ vs. $19.4 \%, \mathrm{p}=0.001$ after matching. This suggests that baseline and hospital characteristics played a key role in the variance of outcomes between the two groups.

\section{Limitations}

Our study has a number of limitations. (1) The NIS is an administrative database that gathers data for billing purposes and can be limited by erroneous coding. Nevertheless, the Healthcare Cost and Utilization Project's quality control minimizes the discrepancies related to diagnosis coding. Also, both the procedures and the hard clinical endpoints reported in our study are hard to miscode. (2) Angiographic data, and information on peri-procedural hemodynamics, medications use, are not available in the
NIS. (3) Similarly, granular data on blood glucose levels, and insulin use as well as the timing of the DKA/HHS diagnoses are not captured in NIS. (5) Pre-admission diabetic control and anti-diabetic medications are not included in this dataset. Several studies have suggested a possible impact of Metformin and other anti-diabetics on infarct size and outcomes in diabetic patients admitted with STEMI [27-29]. This potential effect can not be assessed with the current study design. (4) Significant differences in baseline risk profiles were noted between the two groups. The impact of unmeasured confounders on the comparative analysis cannot be ruled out. Nonetheless, we believe that our rigorous propensity score matching should minimize that risk.

\section{Conclusions}

Decompensated diabetes complicates $\sim 1.5 \%$ of STEMI admissions in diabetic patients. It is associated with lower rates of referral for angiography and revascularization, and a negative differential impact on in-hospital morbidity and mortality and cost. Further studies are needed to identify preventative and management strategies to mitigate the excess morbidity and mortality in these patients.

\section{Additional file}

Additional file 1: Table S1. Variables used for propensity score matching. Table S2. Baseline characteristics of the propensity matched groups. Table S3. Management patterns in the propensity matched cohorts. Figure S1. Standardized mean differences before and after propensity score matching.

\section{Authors' contributions}

$\mathrm{MI}$ and FA designed the study, acquired the database and performed the statistical analysis. CB, MAH and TB performed the background search, and drafted the manuscript. MA supervised the study and made critical revisions of the manuscript. All authors read and approved the final manuscript.

\section{Author details \\ ${ }^{1}$ Department of Medicine, West Virginia University, Morgantown, WV, USA. ${ }^{2}$ Division of Cardiology, West Virginia University, Morgantown, WV, USA. ${ }^{3}$ West Virginia University Heart \& Vascular Institute, 1 Medical Drive, Morgantown, WV 26505, USA.}

\section{Acknowledgements \\ None.}

Competing interests

The authors declare that they have no competing interests.

Availability of data and materials

The data will be made available upon request for other research for the purpose of reproducing the study's results.

\section{Consent for publication}

Was also waived because the data are derived from a nationwide de-identified database. 


\section{Disclosures}

None of the authors have any competing interests or disclosures relevant to this study.

\section{Ethics approval and consent to participate}

The institutional review board approved this study. Informed consent requirements were waived because the data are derived from a nationwide publically available de-identified database.

\section{Funding}

No funding was received for this study.

\section{Publisher's Note}

Springer Nature remains neutral with regard to jurisdictional claims in published maps and institutional affiliations.

\section{Received: 30 April 2018 Accepted: 6 July 2018}

Published online: 17 July 2018

\section{References}

1. Hao Y, Lu Q, Li T, Yang G, Hu P, Ma A. Admission hyperglycemia and adverse outcomes in diabetic and non-diabetic patients with non-STelevation myocardial infarction undergoing percutaneous coronary intervention. BMC Cardiovasc Disord. 2017;17:6.

2. Bessonov IS, Kuznetsov VA, Potolinskaya YV, Zyrianov IP. Sapozhnikov SS [Impact of hyperglycemia on the results of percutaneous coronary interventions in patients with acute ST-segment elevation myocardial infarction]. Ter Arkh. 2017;89:25-9.

3. Chen PC, Chua SK, Hung HF, Huang CY, Lin CM, Lai SM, Chen YL, Cheng JJ, Chiu CZ, Lee SH, Lo HM, Shyu KG. Admission hyperglycemia predicts poorer short- and long-term outcomes after primary percutaneous coronary intervention for ST-elevation myocardial infarction. J Diab Invest. 2014;5:80-6.

4. Ota S, Tanimoto T, Orii M, Hirata K, Shiono Y, Shimamura K, Matsuo Y, Yamano T, Ino Y, Kitabata H, Yamaguchi T, Kubo T, Tanaka A, Imanishi T, Akasaka T. Association between hyperglycemia at admission and microvascular obstruction in patients with ST-segment elevation myocardial infarction. J Cardiol. 2015:65:272-7.

5. Kocas C, Abaci O, Halil GS, Arslan S, Cetinkal G, Bostan C, Coskun U, Yildiz A, Ersanli M. Admission hyperglycemia is associated with failed reperfusion following fibrinolytic therapy in patients with STEMI: results of a retrospective study. Am J Cardiovasc Drugs. 2015;15:35-42.

6. Chang J, Zhang G, Zhang L, Hou YP, Liu XL, Zhang L. High admission glucose levels increase Fas apoptosis and mortality in patients with acute ST-elevation myocardial infarction: a prospective cohort study. Cardiovasc Diabetol. 2013;12:171.

7. Planer D, Witzenbichler B, Guagliumi G, Peruga JZ, Brodie BR, Xu K, Fahy M, Mehran R, Stone GW. Impact of hyperglycemia in patients with ST-segment elevation myocardial infarction undergoing percutaneous coronary intervention: the HORIZONS-AMI trial. Int J Cardiol. 2013;167:2572-9.

8. Zhang JW, Zhou YJ, Cao SJ, Yang Q, Yang SW, Nie B. Impact of stress hyperglycemia on in-hospital stent thrombosis and prognosis in nondiabetic patients with ST-segment elevation myocardial infarction undergoing a primary percutaneous coronary intervention. Coron Artery Dis. 2013:24:352-6.

9. Tsuchida K, Nakamura N, Soda S, Sakai R, Nishida K, Hiroki J, Kashiwa A, Fujihara Y, Kimura S, Hosaka Y, Takahashi K, Oda H. Relationship between glucose fluctuations and ST-segment resolution in patients with STelevation acute myocardial infarction. Int Heart J. 2017;58:328-34.

10. Eitel I, Hintze S, de Waha S, Fuernau G, Lurz P, Desch S, Schuler G, Thiele H. Prognostic impact of hyperglycemia in nondiabetic and diabetic patients with ST-elevation myocardial infarction: insights from contrast-enhanced magnetic resonance imaging. Circ Cardiovasc Imaging. 2012;5:708-18.

11. Birkhead J, Weston C, Timmis A, Chen R. The effects of intravenous insulin infusions on early mortality for patients with acute coronary syndromes who present with hyperglycaemia: a matched propensity analysis using data from the MINAP database 2008-2012. Eur Heart J Acute CardiovasC Care. 2015:4:344-52.
12. Hoebers LP Damman P Claessen BE Vis MM, Baan J Ir van Straalen JP Fischer J, Koch KT, Tijssen JG, de Winter RJ, Piek JJ, Henriques JP. Predictive value of plasma glucose level on admission for short and long term mortality in patients with ST-elevation myocardial infarction treated with primary percutaneous coronary intervention. Am J Cardiol. 2012;109:53-9.

13. Djordjevic-Radojkovic D, Koracevic G, Stanojevic D, Damjanovic M, Apostolovic S, Pavlovic M. Stress hyperglycemia in acute ST-segment elevation myocardial infarction is a marker of left ventricular remodeling. Acute Card Care. 2013:15:38-43.

14. Jensen CJ, Eberle HC, Nassenstein K, Schlosser T, Farazandeh M, Naber CK, Sabin GV, Bruder O. Impact of hyperglycemia at admission in patients with acute ST-segment elevation myocardial infarction as assessed by contrast-enhanced MRI. Clin Res Cardiol. 2011;100:649-59.

15. Sarazawa K, Nakano A, Uzui H, Mitsuke Y, Geshi T, Okazawa H, Ueda T, Lee JD. Acute hyperglycemia causes microvascular damage, leading to poor functional recovery and remodeling in patients with reperfused STsegment elevation myocardial infarction. J Nucl Cardiol. 2012;19:507-14.

16. Ertelt K, Brener SJ, Mehran R, Ben-Yehuda O, McAndrew T, Stone GW. Comparison of outcomes and prognosis of patients with versus without newly diagnosed diabetes mellitus after primary percutaneous coronary intervention for st-elevation myocardial infarction (the HORIZONS-AMI Study). Am J Cardiol. 2017;119:1917-23.

17. Savonitto S, Morici N, Cavallini C, Antonicelli R, Petronio AS, Murena E, Olivari Z, Steffenino G, Bonechi F, Mafrici A, Toso A, Piscione F, Bolognese $L$, De Servi S. One-year mortality in elderly adults with non-ST-elevation acute coronary syndrome: effect of diabetic status and admission hyperglycemia. J Am Geriatr Soc. 2014;62:1297-303.

18. Lazaros G, Tsiachris D, Vlachopoulos C, Chrysohoou C, Milkas A, Papageorgiou N, Tousoulis D, Stefanadis C. Distinct association of admission hyperglycemia with one-year adverse outcome in diabetic and non-diabetic patients with acute ST-elevation myocardial infarction. Hell J Cardiol. 2013:54:119-25.

19. Hritani A, Jan MF, Schleis G, Zehrer T, Olet S, Ammar KA, Allaqaband S. Clinical features and prognosis of type ii myocardial infarction in acutely decompensated diabetes patients. Am J Med. 2018;131(7):820-8.

20. Eubanks A, Raza F, Alkhouli M, Glenn AN, Homko C, Kashem A, Bove A Clinical significance of troponin elevations in acute decompensated diabetes without clinical acute coronary syndrome. Cardiovasc Diabetol. 2012;11:154.

21. Quan H, Li B, Saunders LD, Parsons GA, Nilsson Cl, Alibhai A, Ghali WA, Investigators I. Assessing validity of ICD-9-CM and ICD-10 administrative data in recording clinical conditions in a unique dually coded database. Health Serv Res. 2008;43:1424-41.

22. Agarwal M, Agrawal S, Garg L, Mohananey D, Garg A, Bhatia N, Lavie CJ. National trends in the incidence, management, and outcomes of heart failure complications in patients hospitalized for ST-segment elevation myocardial infarction. Mayo Clin Proc. 2017;1:26-36.

23. Berman N, Jones MM, De Coster DA. 'Just like a normal pain', what do people with diabetes mellitus experience when having a myocardial infarction: a qualitative study recruited from UK hospitals. BMJ Open. 2017:7:e015736.

24. Reinstadler SJ, Stiermaier T, Eitel C, Metzler B, de Waha S, Fuernau G, Desch S, Thiele H, Eitel I. Relationship between diabetes and ischaemic injury among patients with revascularized ST-elevation myocardial infarction. Diab Obes Metab. 2017:19:1706-13.

25. Esposito K, Nappo F, Marfella R, Giugliano G, Giugliano F, Ciotola M, Quagliaro L, Ceriello A, Giugliano D. Inflammatory cytokine concentrations are acutely increased by hyperglycemia in humans: role of oxidative stress. Circulation. 2002;106:2067-72.

26. Marfella R, Verrazzo G, Acampora R, La Marca C, Giunta R, Lucarelli C, Paolisso G, Ceriello A, Giugliano D. Glutathione reverses systemic hemodynamic changes induced by acute hyperglycemia in healthy subjects. Am J Physiol. 1995;268:E1167-73.

27. Hesen NA, Riksen NP, Aalders B, Ritskes-Hoitinga M, El Messaoudi S, Wever KE. A systematic review and meta-analysis of the protective effects of metformin in experimental myocardial infarction. PLoS ONE. 2017;12:e0183664.

28. Lexis CP, van der Horst IC, Lipsic E, Wieringa WG, de Boer RA, van den Heuvel AF, van der Werf HW, Schurer RA, Pundziute G, Tan ES, Nieuwland W, Willemsen HM, Dorhout B, Molmans BH, van der Horst-Schrivers AN, Wolffenbuttel BH, ter Horst GJ, van Rossum AC, Tijssen JG, Hillege HL, de 
Smet BJ, van der Harst P, van Veldhuisen DJ, Investigators G-I. Effect of metformin on left ventricular function after acute myocardial infarction in patients without diabetes: the GIPS-III randomized clinical trial. JAMA. 2014;311:1526-35.
29. Chinda K, Palee S, Surinkaew S, Phornphutkul M, Chattipakorn S, Chattipakorn N. Cardioprotective effect of dipeptidyl peptidase-4 inhibitor during ischemia-reperfusion injury. Int J Cardiol. 2013;167:451-7.
Ready to submit your research? Choose BMC and benefit from:

- fast, convenient online submission

- thorough peer review by experienced researchers in your field

- rapid publication on acceptance

- support for research data, including large and complex data types

- gold Open Access which fosters wider collaboration and increased citations

- maximum visibility for your research: over 100M website views per year

At BMC, research is always in progress.

Learn more biomedcentral.com/submissions 